\title{
Industrial Information Application for the Production Process
}

\author{
Dominika Palašcáková* , Peter Demeč \\ Technical University of Košice, Faculty of Mechanical Engineering, Department of production technology, Boženy Němcovej 32, \\ 04200 Košice, Slovak Republik
}

\section{BIOGRAPHICAL NOTES}

Dominika Palaščáková, Ing., PhD., born $4^{\text {th }}$ January 1982, graduated from the Technical University of Košice, Faculty of Mechanical Engineering with a seat in Košice, in the field of production technology and robotics, in 2006.

Peter Demeč, prof., Ing., CSc., born 16 th March 1952, graduated from the Technical University of Košice, Faculty of Mechanical Engineering in Košice, in the field of manufacturing machines and equipments, in 1975.

\section{KEY WORDS}

Visualization, MES, SCADA.

\section{ABSTRACT}

The paper focuses on the area software application that helps businesses to significantly increase the production efficiency and the amount of production of products that allows to identify and to quantify the exact causes of production losses caused by inefficient use of their production facilities. The application allows manufacturers to track and analyze the effectiveness of their overall production downtime and machinery, production lines and other equipment in production and obtain as follows detailed information on the efficiency of the production and possible shortcomings with the acquisition in real time directly from the production facilities and production operators. For the evaluation is available, easy to use reports and analytical tools to quickly reveal trouble spots that need to be improved.

\section{INTRODUCTION}

Timely and accurate production information from the production are in today's competitive market environment, the key to the prosperity of the manufacturing firms. The collection and storage of information of the production is the first necessary step in the production process. Then the following information obtained from the production to different optimal decisions for the improvement of the quality of production to control workers, reducing production costs and increasing production.

Global competition and the need to respond quickly to new business opportunities have raised in recent years the need for new developments in the field of industrial automation and information systems architecture. Production and other industrial companies no longer need to create a comprehensive and indivisible software applications, which require a large amount of time for your design, development and deployment. The requirement is flexible and modular solution, in which it is possible to very quickly create or modify existing applications, keeping in mind that the requirements on them or even to the entire application may change in the future. 


\section{Increase Operational Performance in the Production Process}

The concept and functionality of the software products allow for flexibility in the development of large scale, deployment and updates to applications. Users can flexibly adapt and easily expand their production systems in order to meet not only current, but arbitrarily, practically as well as future needs and continuously improve the management, efficiency and effectiveness of production.

Software architecture for efficient design and operation of the application provides automation and information solutions for:

- Visualization and application of type supervisory HMI (Human-Machine Interface) - visualization and supervisory management/human-machine interface.

- Supervisory and visualization applications, SCADA/Geo-SCADA (Supervisory Control and Data Acquisition) - the management and collection of data, including extensive technological units.

- Applications for advanced management and analysis of the production operations of the Production and Performance Management category - production management and analysis of the performance of the production, or MES (Manufacturing Execution Systems).

With the help of the software, you create an advanced technological information system, which is closely connected with its own production in the manufacturing process. Software so aptly complements the administrative business information systems, human resources and finance on trade logistics. The necessary information is provided to the workers of various levels of the enterprise, and not only horizontally, but also vertically, i.e. from the production operators to the management of the undertaking. It is broken down by production enterprises in the usual barriers between the world and help to meet the requirements of the various certificates and customer audits.

The most important features include:

- collect data from control systems,

- visualization and supervízne solution of technological processes,

- adherence to production processes,

- the actual production history and record all the important technological parameters,

- analysis and documentation of the actual course production processes (family tree), detailed tracking of production and management (MES),

- static quality management of production processes,

- tracking and analysis of production downtime,

- calculation of the total efficiency of the production facilities,

access to production information both inside and outside the workplace (Internet).

Software module helps producers improve the operational performance of their operation, the integration of branded products and the ability of the environment to the inner requirements of rapid reaction, [1]. The application of the module ensures consistent operation of machinery or production lines improves the reliability and repeatability of the final settings of the parameters prescribed production equipment and allow for a detailed analysis of all the events in their own production and recording.

\section{Program system allows you to:}

- ensure the right parameters for consistent production in order to maintain consistency and quality production manufacturing operations accompanying the branded products,

- improve the reliability and repeatability of production facilities to increase the flexibility of production settings and reducing production scrap,

- a detailed record of all relevant production auto events (actual production history) into an electronic database,

a detailed analysis and documentation during the production, including the production of pedigrees, bidirectional,

- rapid feedback control of specific products and the identification of the causes of any problems,

- to meet Government or institutional regulations and directives intended to protect public health and safety,

- easy application changes or expansion of the system in case of growing requirements,

- ease of integration of the company's trading system with direct management of production thanks to the standard data structure of the snap-in, in accordance with the norm.

\section{Reliability and Homogeneity of Manufacturing Operations}

Software application ensures the homogeneity of the settings and operation of the machinery, 
consistently production lines and detailed records of all important events, which may be available to the production to the level of each individual product. Each production order can be assigned to the specified source or device, such as a particular production unit or production line. It automatically selects the necessary parameters of the production processes and associated with the appropriate adjustment points (set-points) production facilities. During the course of production shall be obtained and stored for detailed information about specific materials that have been used in the manufacture of concrete products. The information on which these products were manufactured, who served the machines and other production-related information that can be sorted according to the flow of production, or the serial numbers of each product. By so called "bloodlines" enabling the tracing back of the complete production history, as shown in figure 1, [2].

\section{Here we can examine the following information:}

- used in production processes and adjusting the points assigned to the production,

- the actual consumption of raw materials that were used and the kind of quantity for each manufacturing batch or a batch of the finished product, including the identification of any of the products or waste,

in the finished products, which was used a feedstock. In the case of additional findings on problems of this raw material so it can instantly and accurately identify all the finished products back,

- the use of specific production equipment for the production of specific products,

- who participated in the production of specific products, operators,

- other events related to a specific part of the manufacturing process, certain equipment or operator, - comparison of planned and actual values of material consumption, operating cycle times, etc.

\section{Recording and analysis of actual production history}

Client access to stored information is made possible through an online information portal. It's production information portal, which gathers production data from various sources, these data appropriately organizes, secures and provides a large number of candidates eligible customer from the Internet / Intranet. Clients do not need to have any

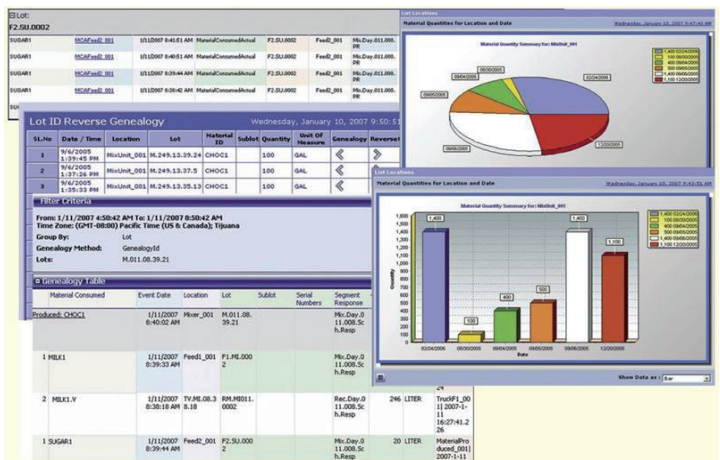

Fig. 1: A variety of options for the analysis of production history reports for all products.

special software installed on your computer.

It turns out that the information is no longer sufficient to provide only the operator and supervisor. Certain information about the status of production in real time, the summary and analysis of the data during the production, and sometimes even the ability to remote control, it is now necessary to make a new category called and everything "casual" users. In the light of to the frequency of access to the data of these users, it is no longer economical to handle their complete system of SCADA/HMI or other special categories of client applications. The system is capable of all of the data and services provided by means of a much simpler interface-a regular browser for the website, figure 2 .

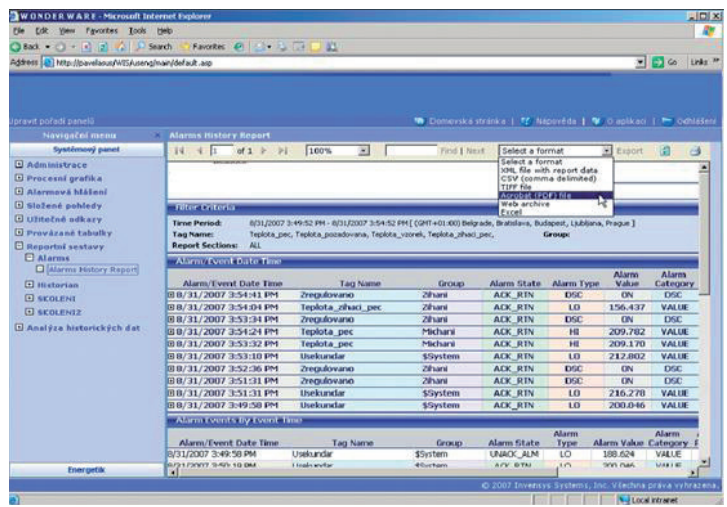

Fig. 2: The report data is stored in a database accessible through the Internet.

Information server allows clients to access live data and alarm (current and historical), figure 3. The client has the possibility to see the portal "in context", which allows him to quickly get an overview of the State of technology. 
Effective protection of published data is further ensured by additional security systems integrated directly in the portal. The panel navigation system allows clients to access only the data that correspond to the declared their vocational focus. The system user role defines the rights of users with respect to the technology (the right entry in the I/O, read-only).

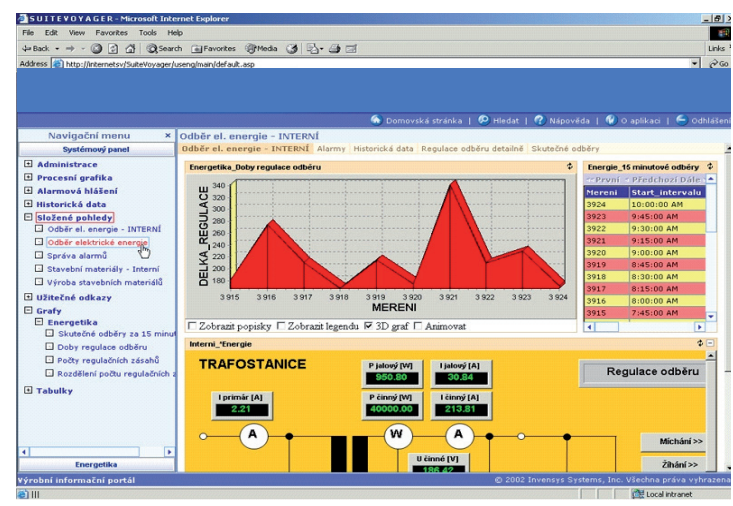

Fig. 3: Graphical display technology with current data

The program not only ensure proper production parameters and helps manufacturers system by the quality and homogeneity of production thanks to the automation of production facilities, but also to meet a series of requirements settings, which are given by different governmental regulations, directives and initiatives intended to protect public health and safety. The complete records of the products in the State "as they were actually produced" are stored in the database, and given the system as soon as available. Users module to meet the requirements of accuracy and quick availability of records on the composition and quality of all its products throughout the life-cycle-from raw materials to the final product, as shown in figure 4 [3].

You can therefore benefit from all the advantages of the application of a coherent philosophy of the entire system using this technological infrastructure for industrial automation and information applications, [4].

The main benefits include:

- collect data from a variety of management systems (independence from a particular brand of hardware automation),

- a distributed client/server system architecture, - central deployment, administration and application-wide Diagnostics,
- high repeatability,

- the use of visualization systems for illustrative graphical user environment,

- easy during development and after deployment, applications, accompany,

- unlimited flexibility and scalability for applications of any size.

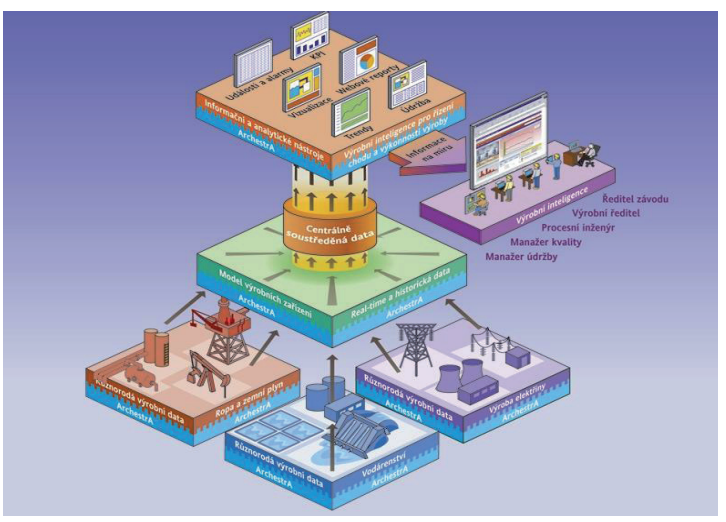

Fig. 4: The architecture of the flow of information in the production.

Thanks to the openness of the architecture can be operated with the new application module and production facilities and control systems from different manufacturers. Thus, there is no loss of previous investments and intellectual knowledge, but rather an extension of the moral life of the developed production systems. The functionality of the solutions can be implemented gradually according to the desired range of functionality and the size of the application. Thanks to the practical system architecture for a solution easily expands to tap the growing demands of the end user.

\section{With Historical Data from the Production Database}

A database management system with historical data is designed for the rapid collection of a large number of technological data from production processes, their effective application and easy provision of different types of client applications, figure 5.

System and related products for the analysis of stored procedures and data access by any interested undertaking to ensure technology exact production information in good time. Data for the first time obtained from production processes are transformed into the information necessary for the 
correct assessment of the situation and understand what and why going on in a production environment. On the basis of these skilled and quick reference of available information can be efficiently convert smart operational and strategic production decisions.

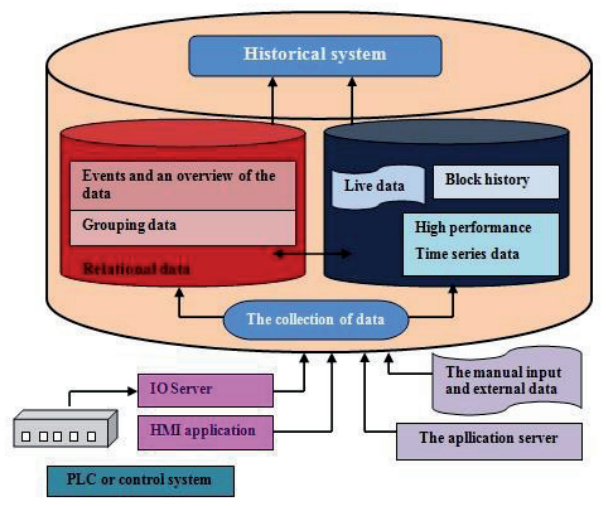

Fig. 5: Architecture of the database with historical data.

Obtained "production intelligence" allows the responsible staff at all levels of the company quickly removed the tiny variations in production and technological processes, and the bigger and on an ongoing basis so to ensure a high quality of production.

\section{The main features and benefits:}

- the collection of large amounts of data from arbitrary data sources, and production process,

- Real-time performance while maintaining the openness of the system relational database,

- efficient compression algorithm minimizes storage space for data storage,

- integrated database providing universal access not only to the procedural and technological data stored, but also to other related data on production,

- the integration with the portal server Information for convenient delivery of targeted information client users-live process graphics, trends over time, reports, analysis, key performance indicators, - support of communication and in an environment of slow and unstable networks,

- compliance with safety requirements,

- support to ensure high availability of the critically important applications,

- solution for immediate deployment and easy use of boxed system.
Strategic concept the server combines the openness of a relational database by using a database system with special optimizations for high performance and efficient storage of data, which are necessary for the processing of large volumes of data and for the movement in real time. The system receives data and stores it in the necessary place. The data from the various sources of production processes in real time and allows you to keep track of them as well as with manual loading or older data with data stored during a network outage or in distributed systems. All information is available in one place and, thanks to the openness of access to data you can easily analyze a large number of different types of client applications, [5].

The system concentrates all necessary data from the production environment. This is the flexibility of the system, how and where will those obtained the required data is collected and stored. All information, regardless of their place of origin, the manner and time fully integrated in the central data store record.

\section{Acknowledgments}

This article was created within the grant project KEGA Nr. 023TUKE-4/2012 Creation of a comprehensive educational - teaching material for the article Production technique using a combination of traditional and modern information technology and e-learning.

\section{References}

[1] Wonderware, Pantek, corporate materials

[2] http://www.pantek.cz/produkty/wonderware-operationssoftware/

[3] http://www.pantek.cz/produkty.php?idproduktu=8\&produ $\mathrm{kt}=$ wonderware-information-server

[4] http://www.pantek.cz/produkty/wonderware-system-platform/

[5] http://www.pantek.cz/produkty/wonderware-performance-software/ 


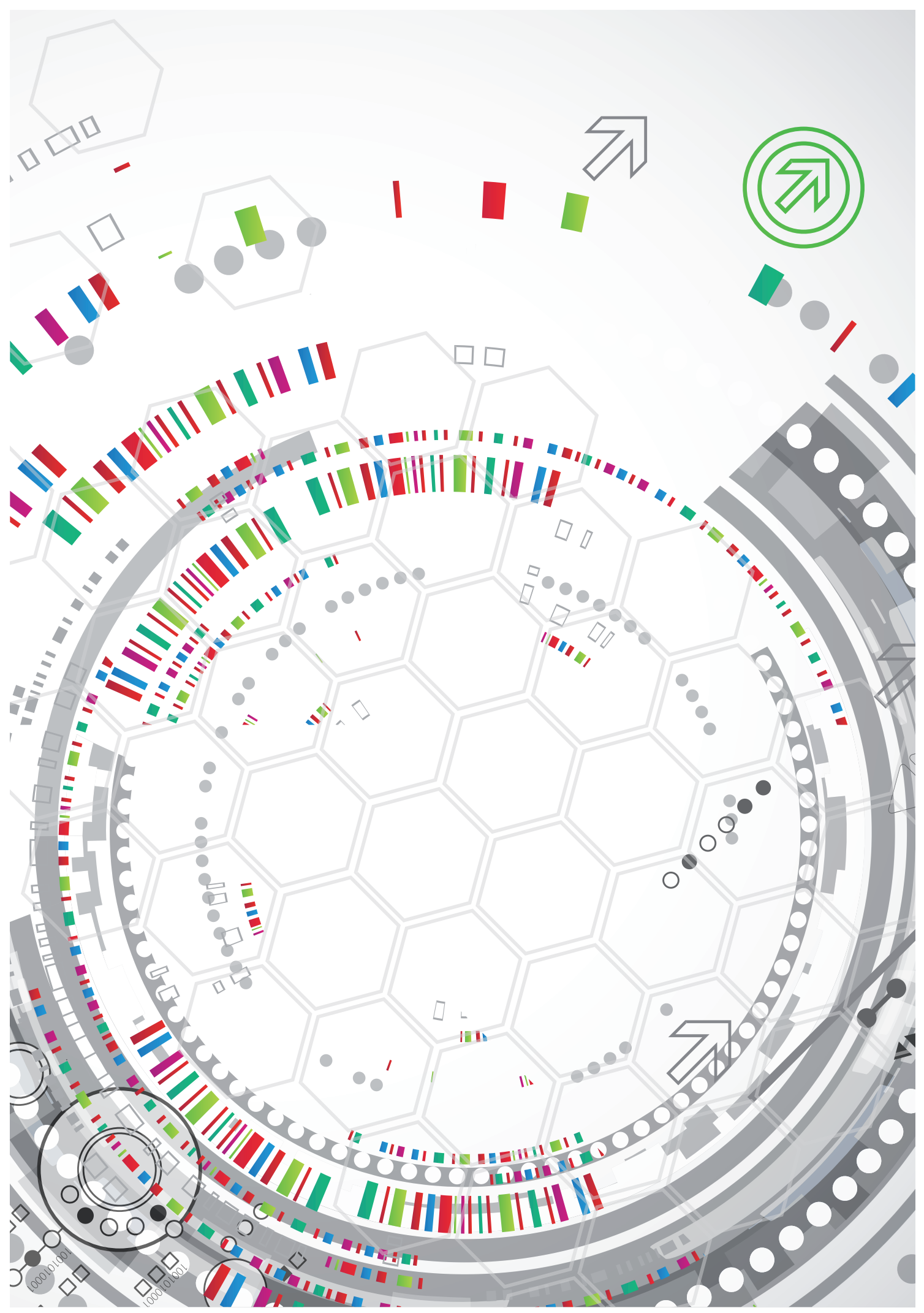

